\title{
Cordiluroides Albuquerque from Costa Rica: first records, descriptions and taxonomic changes (Diptera, Muscidae, Coenosiinae)
}

\author{
Márcia S. Couri ${ }^{1,4}$, Claudio J. B. de Carvalho ${ }^{2,4}$ \& Adrian C. Pont ${ }^{3}$
}

\begin{abstract}
${ }^{1}$ Museu Nacional, Universidade Federal do Rio de Janeiro, Quinta da Boa Vista, 20940-040, Rio de Janeiro-Brazil. mcouri@attglobal.net 2Departamento de Zoologia, Universidade Federal do Paraná, Caixa Postal 19020, 81531-980, Curitiba-Brazil. cjbcarva@ufpr.br ${ }^{3}$ Oxford University Museum of Natural History, Parks Road, Oxford OX1 3PW, U.K. pont.muscidae@btinternet.com ${ }^{4}$ Research fellow of Conselho Nacional de Desenvolvimento Científico e Tecnológico, CNPq
\end{abstract}

\begin{abstract}
Cordiluroides Albuquerque from Costa Rica: first records, descriptions and taxonomic changes (Diptera, Muscidae, Coenosiinae). Cordiluroides Albuquerque is a genus of Neotropical Coenosiinae (Muscidae), known from six species. The genus is here recorded for the first time from Costa Rica, on the basis of three species: C. listrata Albuquerque, 1954, C. insularis (Williston, 1896) and C. bistriata (Wulp, 1896) sp. rev.. We provide a key for the identification of these Costa Rican species, redescribe and illustrate their external morphological characters and terminalia. C. bistriata and $C$. vittifera (Stein, 1904) are both considered to be good species and are re-instated from the synonymy of $C$. insularis. The type material of $C$. listrata (Museu Nacional, Rio de Janeiro), of $C$. insularis and C. bistriata (The Natural History Museum, London) and of C. vittifera (Museum für Naturkunde, Humboldt-Universität zu Berlin) has been examined.
\end{abstract}

KEYWORDS. Morphology; descriptions; terminalia; taxonomy.

RESUMO. Cordiluroides Albuquerque da Costa Rica: primeiros registros, descrições e mudanças taxonômicas (Diptera, Muscidae, Coenosiinae). Cordiluroides Albuquerque é um gênero neotropical de Coenosiinae (Muscidae), conhecido por seis espécies. O gênero é registrado pela primeira vez na Costa Rica, através de três espécies: C. listrata Albuquerque, 1954, C. insularis (Willliston, 1896) e C. bistriata (Wulp, 1896) sp. rev.. Uma chave para identificação das espécies da Costa Rica é fornecida, bem como a redescrição das três espécies e ilustrações de caracteres morfológicos e da terminália. C. bistriata e $C$. vittifera (Stein, 1904) são consideradas boas espécies e por isso removidas da sinonímia de $C$. insularis. O material-tipo de $C$. listrata (Museu Nacional, Rio de Janeiro), de $C$. insularis e $C$. bistriata (The Natural History Museum, London) e de C. vittifera (Museum für Naturkunde, Humboldt-Universität zu Berlin) foi examinado.

PALAVRAS CHAVE. Morfologia; descrição; terminália; taxonomia.

Cordiluroides Albuquerque, 1954 is a Neotropical genus with six described species: C. geniculata (Macquart, 1851), C. listrata Albuquerque, 1954, C. megalopyga Albquerque, 1954 and C. paulistensis Couri \& Gonçalves, 2002, all four from Brazil; C. bicolor (Bigot, 1885) from Mexico; and C. insularis (Williston, 1896) known from Mexico, St. Vincent Is., Colombia, Peru and Bolivia (Couri \& Gonçalves 2002; Carvalho et al. 2005).

In the identification key to the Neotropical genera of the Muscidae (Carvalho \& Couri 2002), Cordiluroides is close to Neodexiopsis Malloch from which it can be distinguished by the position of the antennal insertion (above the mid level of the eye), by the presence of only one pair of postsutural intraalar setae, and by the transverse lower calypter. Albuquerque (1954) also mentioned the elongated abdomen of Cordiluroides. According to him, the genital segments of $C$. listrata and of C. neotropica Albuquerque, 1954 (now considered to be a junior synonym of $C$. listrata) are different in appearance from those of Neodexiopsis, but C. megalopyga, although having the same external morphological characters as the other species of Cordiluroides, has genitalia similar to those of Neodexiopsis.

Cordiluroides is placed in the tribe Coenosiini and, according to Couri \& Pont (2000), forms a monophyletic clade together with Neodexiopsis and Haroldopsis Albuquerque, 1954 , sharing one synapomorphous character state (hind femur with three preapical dorsal setae). The species of the genus can be separated by the keys given by Couri \& Pamplona (1992) and Couri \& Carvalho (2002).

The aim of this paper is to record the presence of Cordiluroides in Costa Rica for the first time, on the basis of three species. The analysis of this material has also led to the proposal of some taxonomic changes.

\section{MATERIALAND METHODS}

The majority of the material studied in this paper was collected recently in Costa Rica, as part of a project to compile an inventory of the Diptera of Costa Rica ("Plan de siete años para um inventario de los dípteros de Costa Rica"), under the international coordination of Dr. Manuel A. Zumbado (Instituto Nacional de Biodiversidad, INBC, Costa Rica). CJBC visited the collection and sorted the material that we report on here.

To support the results, the type material of $C$. listrata, $C$. insularis, C. bistriata and C. vittifera was examined. 
The terminalia were macerated in a solution of $10 \%$ potassium hydroxide, and then boiled in a water-bath for ten minutes. They were then dissected in glycerol, drawn, stored in a microtube with glycerol, and attached to the pin bearing the specimen.

The material examined is deposited in the following institutions: Instituto Nacional de Biodiversidad, Costa Rica (INBC); Museu Nacional, Rio de Janeiro (MNRJ), Departamento de Zoologia, Universidade Federal do Paraná, Curitiba (DZUP), Museum für Naturkunde, HumboldtUniversität zu Berlin (ZMHB), and The Natural History Museum, London (BMNH).

\section{RESULTS ANDDISCUSSION}

Three species of Cordiluroides are here recorded from Costa Rica: C. listrata, $C$. insularis and $C$. bistriata. As $C$. listrata is well known from recent descriptions in the literature, we give only a brief diagnosis and a list of the material examined. For the other two species, redescriptions with illustrations of the male and female terminalia are given.

Both $C$. bistriata and $C$. vittifera have for long been considered to be junior synonyms of $C$. insularis (see Carvalho et al., 2005). However, examination of the female syntypes of $C$. bistriata shows that it is a species distinct from $C$. insularis, and so we are reinstating and redescribing it in this paper. The original description of both sexes of $C$. vittifera together with examination of the only surviving syntype (ZMHB) shows that this too is a distinct species, but we do not discuss it in detail here as we have not seen it from Costa Rica. C. insularis is also redescribed from the male and female sexes (males syntype examined).

All three species can be easily distinguished by the combination of the colour pattern of legs, abdomen and wings and by the morphology of the terminalia.

Key to the Costa Rican species of Cordiluroides

1. Abdomen of male very elongated, tergites $1+2$ and 3 translucent yellow and with a median dorsal triangular brown cloud; tergites 4 and 5 brown, sometimes tergite 4 also translucent yellow at base (Figs 1 and 2 ); abdomen of female not elongated, brown, with lateral areas yellow on tergites $1+2$ and 3 and grey pollinose on tergites 4 and 5 (Fig. 3); wings smoky (Fig. 1), especially on apical third [Mexico, Peru, Costa Rica (new record)] ........................... C. bistriata (Wulp)

Abdomen of male and female not as described above; wings smoky or hyaline

2. Abdomen of male and female shining brownish-black with little grey pollinosity (Figs 4 and 5); wings smoky [Brazil (Rio de Janeiro), Costa Rica (new record), St. Vincent Is., Colombia, Bolivia] ..

C. insularis (Williston)

Abdomen of male and female brown with grey pollinosity and brown clouds on tergites, some males with tergites $1+2$ and 3 with yellow marks; wings hyaline [Brazil (Rio de Janeiro), Costa Rica (new record)] ..... C. listrata Albuquerque

\section{C. listrata Albuquerque, 1954}

Cordiluroides listrata Albuquerque, 1954: 364, figs 8 15. Holotype male, MNRJ, paratypes MNRJ. Type locality: Brazil, Rio de Janeiro. Distribution: Brazil.

Diagnosis. Legs dark brown with trochanters and femurotibial joints yellow; abdomen of male and female brown with grey pollinosity and brown clouds on tergites, some males with tergites $1+2$ and 3 with yellow marks; wings hyaline.

Material examined. COSTA RICA: Prov. Guanacaste, Estação Pitilla, 700 m, 9 Km, S. Santa Cecília, Jan 1989, GNP Biodiversity Survey W85 25'40", N 10 59'26", INBIO CRI 001 049265, 1 female (INBC); INBIO CRI 001 049399, 1 female (DZUP); INBIO CRI 0010498935 , 1 female (INBC); INBIO CRI 001 049331, 1 female BMNH; INBIO CRI 001 049590, 1 male (INBC). 11-30 ENE 1993. P. Rios; INBIO CRI 001 675980, 1 female (DZUP); INBIO CRI 001 138522, 1 female (MNRJ); oct 1994, P. Rios; INBIO CRI 002 123328, 1 male (MNRJ). Est. Las Pailas. P. N. Rincón de la Vieja, 800 m, 10-13 mar 1994. K. Taylor; INBIO CRI 001 749594, 1 female (BMNH); INBIO CRI 001 749567, 1 male dissected (INBC); Tilarán, P.N.V. Tenório, Send. Rancho Capú, Cerca Torres Eléctricas, 740 m. 23 nov 2000. J. Gutiérrez; INB0003117329 INBIOCRI , 1 female (INBC); Rio San Lorenzo, Tierras Morenas, Tenório A.C.A. 1050 m. 7-9 feb 1994. N. Obando; INBIO CRI 001 745526, 1 female (INBC). Prov. Cartago. P.N. Tapanté, Macizo de la Muerte Quebrada Segundo, 1200-1300, 22 oct 2002, M. Alfaro, Red de Golpe; INB0003543611 INBIOCRI, 1 female dissected (INBC). Prov. Alagie, Sect. San Ramon de Dos Rios, 620 m, 20 FEB 5 mar 1995. F. A. Quesada; INBIO CRI 002, 138522, 1 female (INBC); INBIO CRI 002, 138521, 1 male (INBC). Prov Alaj. Lado S Laguna Arenal, 500 m, Túnel Del ICÊ, D. Jansen, ENE 1989; INBIO CRI 000 627918, 1 female (INBC); INBIO CRI 000 627806, 1 female (INBC); Prov. San Jose. Est. Bijagual, 500 m. Res. Biol. Carará. JAN 1990, R. Zuniga 192250 474760. INBIO CRI 000 208202, 1 male (without head) (INBC).

Comments: The species was previously known only from Brazil (Rio de Janeiro). This is the first record from Costa Rica.

C. bistriata (Wulp, 1896), sp.rev.

(Figs. 1-3, 6-13)

Coenosia bistriata Wulp, 1896: 343 (key) [and 1897: 345] (Coenosia). Syntypes 4 females, BMNH, syntype 1 male, not located. Type locality: Mexico, Orizaba and Teapa in Tabasco. Doubtfully synonymised with $C$. insularis by Stein (1919:160); this synonymy confirmed by Pont (1972: 44).

Colour. Head with frons brown, face, fronto-orbital plate and gena silvery; antenna and arista brown, apex of pedicel lighter in some specimens; palpus brown. Scutum brown with grey pollinosity, with 2 large lateral vittae. Upper calypter brown, lower one white; halter yellow. Wing infuscated (Fig. 1). Legs with fore coxa yellow, mid and hind coxae grey pollinose, fore femur brown with basal third and apex yellow, mid and hind femora brown with basal third yellow, fore tibia yellow, mid and hind tibiae brown, tarsi brown, a little darker than mid and hind tibiae (Fig. 1). Pulvilli yellowish-white; claws black. 

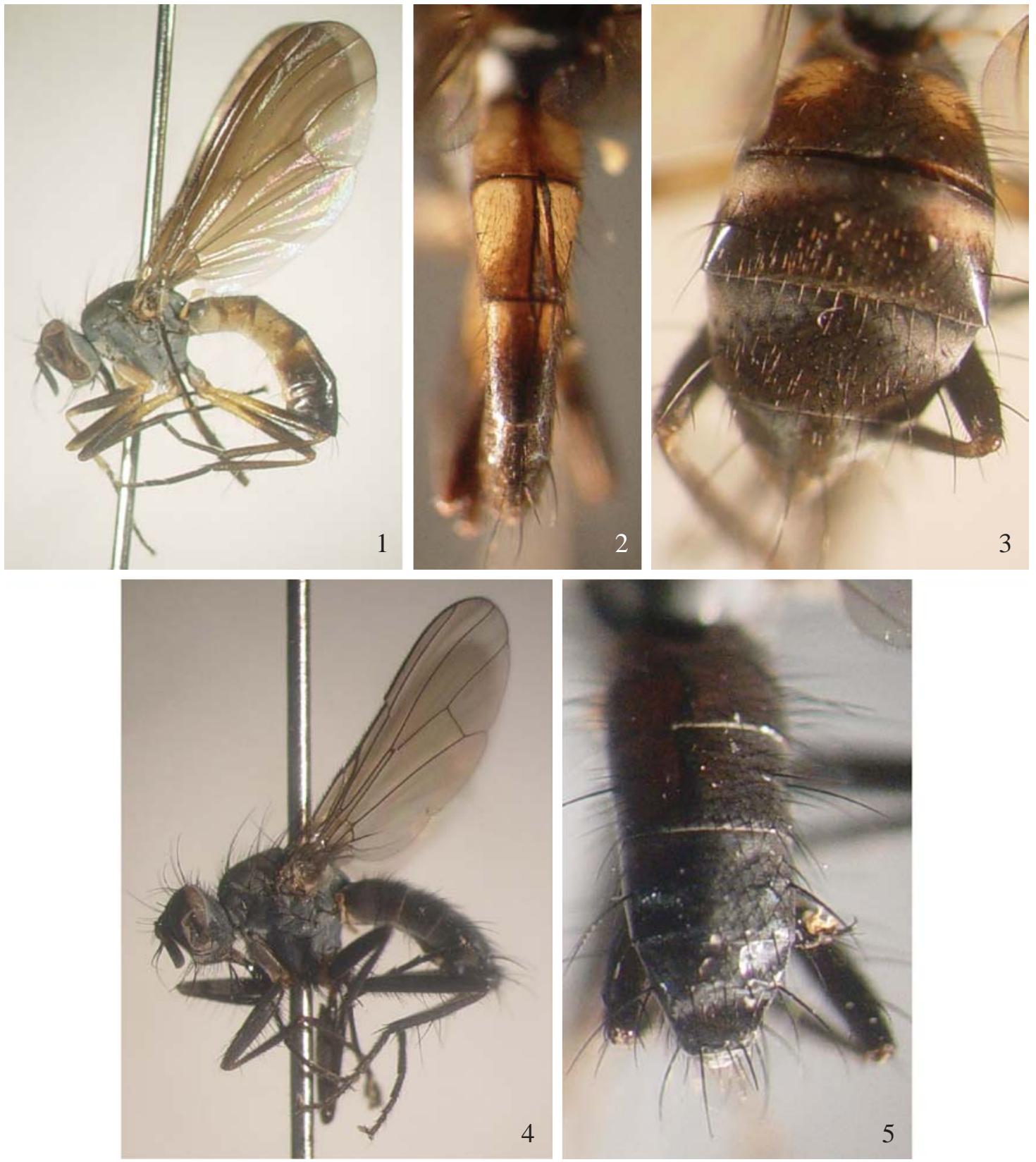

Figs. 1-5. 1-3, Cordiluroides bistriata (Wulp). 1, Male, lateral view; 2, Male, abdomen, dorsal view; 3, Female, abdomen, dorsal view. 4-5, Cordiluroides insularis (Williston). 4, Male, lateral view; 5, Male, abdomen, dorsal view.

Abdomen of male (Fig. 2) with tergites $1+2$ and 3 yellow, except for a median triangular brown area and a long brown area on distal margin; tergites 4 and 5 wholly brown. Abdomen of female (Fig. 3) brown, tergites $1+2$ and 3 with yellow lateral areas and tergites 4 and 5 with grey pollinosity on lateral basal areas.

Length. Male: body: $9-11 \mathrm{~mm} \mathrm{~mm}$; wing: $8-9 \mathrm{~mm}$

Head. Interocular space about one-third of head-width at level of anterior ocellus. Three pairs of inclinate frontal setae, the lower two medium sized, the other one long; one pair of long reclinate orbital setae. Ocellar setae long, similar in length to the reclinate orbital. Antennae inserted a little above middle of eyes; flagellomere about 4 times as long as pedicel. Arista short-pubescent. Cheek narrow. Vibrissa strong and long. Proboscis with developed teeth (Fig. 6)

Thorax. Acrostichal setulae in 1-2 irregular rows, prescutellar pair not developed; dorsocentral setae $1+3$, all long and similar in length; 2 postpronotals, inner one short and delicate, outer one long; 1 presutural and 1 postsutural intra-alars; 1 presutural and 2 postsutural supra-alars. Scutellum with both basal and apical pair of setae long. Notopleuron with two setae, anterior one a little longer than posterior one. Anepisternum with a row of about 5-6 setae. Lower calypter about 1.6 as long 


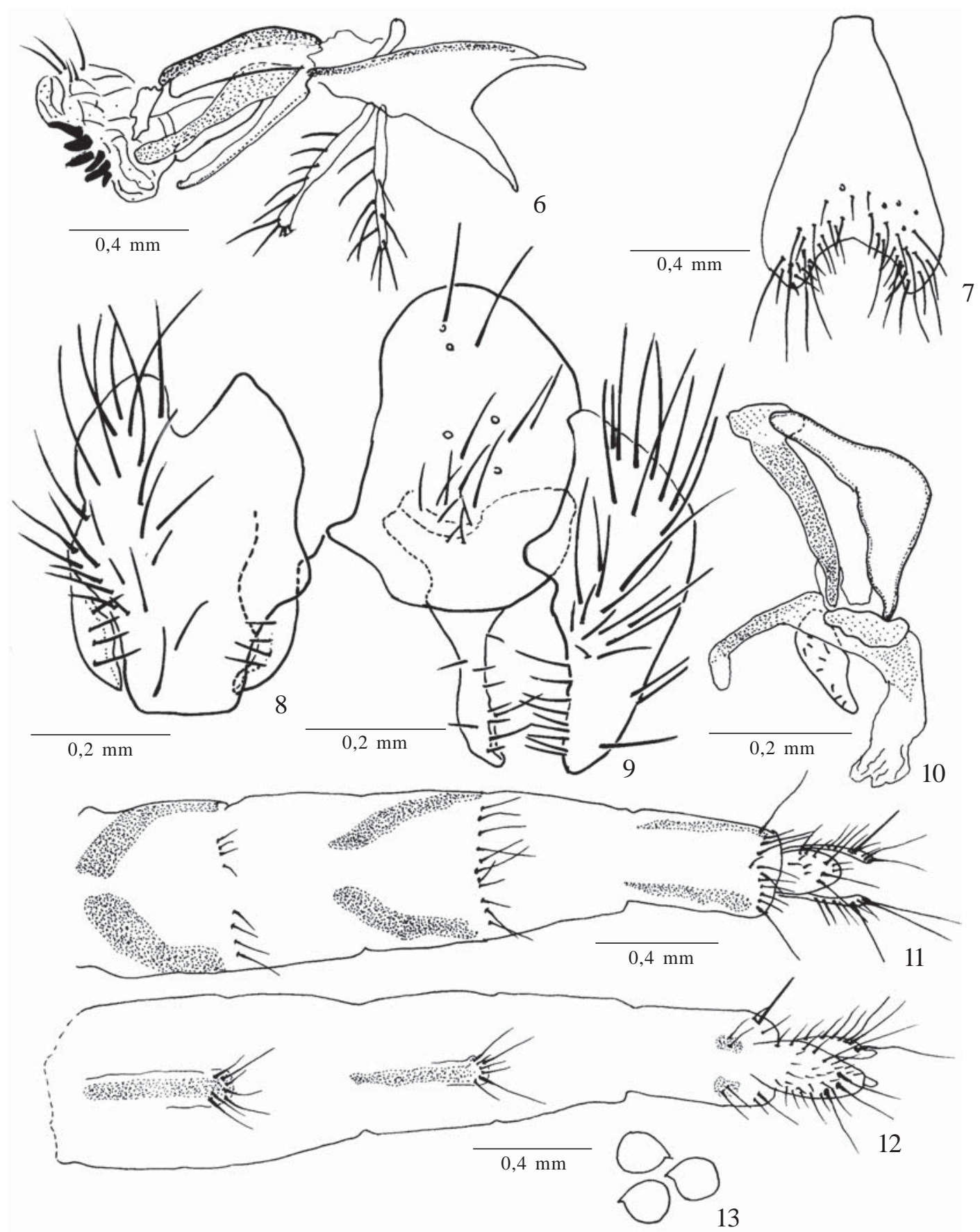

Figs. 6-13. Cordiluroides bistriata (Wulp). 6, Proboscis of male, lateral view; 7, Sternite 5, male, dorsal view; 8, Cercal plate and surstyli, dorsal view; 9, Epandrium, cercal plate and surstyli, lateral view; 10, Phallic complex, lateral view; 11, Ovipositor, dorsal view; 12, Ovipositor, ventral view; 13, Spermathecae.

as upper one. Fore femur with a row of sparse bristles on posterodorsal and posteroventral surfaces. Fore tibia with one long median posterior seta; one preapical dorsal, one posterior preapical and one posteroventral apical, these three short. Mid femur with 3-5 anterior setae on basal two-thirds, posteroventral surface with 3-5 long sparse setae on basal two-thirds; posterior surface with two preapical setae. Mid tibia with a submedian anterior to anterodorsal seta, a long median posterior seta, one dorsal preapical seta, and apical setae on anterior and ventral surfaces, the latter strong. Hind femur with long, fine and sparse setae on anteroventral and posteroventral surfaces; one dorsal and one posterdorsal preapical setae. Hind tibia with a median anterodorsal and one preapical, dorsal surface with one preapical seta, shifted well away from the tip of the tibia.

Abdomen. Elongated. Tergites 2-3 each with one pair of 
lateral setae; tergite 5 with a row of marginal and discal setae. Sternite 5 triangular (Fig. 7).

Terminalia. Surstyli shorter than cercal plate (Figs 8 and 9). Aedeagus as in Fig. 10, hypandrium elongated.

Female. Similar to male in most respects. Abdomen not elongated.

Terminalia: Ovipositor long with microtrichia along its whole length, tergites fine, cerci long (Figs. 11 and 12). Three round spermathecae (Fig. 13).

Discussion. The colour of the abdomen and the elongation of the male abdomen easily distinguish this species from the others here recorded from Costa Rica.

Coenosia vittifera was synonymised with $C$. bistriata by Stein (1918: 243) and with C. insularis by Pont (1972: 44). However, examination of the sole surviving syntype female in ZMHB, from Peru (Callanga), has shown that $C$. vittifera too is a distinct species. It differs from $C$. bistriata as follows: upper calypter yellow; femora wholly dark brown; tibiae yellow on basal quarter, otherwise dark brown; arista short haired, the longest combined pubescence almost equal to width of antennal flagellomere.

Material examined: COSTA RICA: Prov. Puntarenas, R. I., Ujarrás - Salitre - Cabagra, de Tararia a Cerro Nai, 3129m, 1 male (INBC), 17 abr 2002, M. Alfaro, Libre; INB0003460700 INBIOCRI; INB0003460697 INBIOCRI, 1 male (INBC); INB0003460647 INBIOCRI, 1 male (BMNH) B0003460699 INBIOCRI, 1 male (DZUP); INB0003460698 INBIOCRI, 1 male (INBC); INB0003460696 INBIOCRI, 1 male dissected (INBC); INB0003460701 INBIOCRI, 1 female dissected (INBC); INB0003460695 INBIOCRI, 1 male (INBC); INB0003460702 INBIOCRI, 1 female (DZUP). P. Int. La Amistad, Cerro Hoffman, 2460 m, 24 mar 2003, R. Gonzáles, red de Golpe; INB0003717312 INBIOCRI, 1 male (MNRJ); INB0003717306 INBIOCRI, 1 male (INBC); Cerro Pecón a Três Colinas, 2124m, 17 ABR 2002, M. Alfaro, Libre; INB0003479914 - INBIOCRI, 1 male (INBC). Buenos Aires, Estación Altamira, 1500, 21-23 nov 1995. E. Navarro; INB0003310508 INBIOCRI, 1 male (INBC). Prov. Limón, P.I.L.A. Est. Valle del Silencio, 2475m, 26-30 mar 2003. R. Delgado, M. Alfaro, R. González, D. Rubí, Tp. De Luz; INB0003713912 INBIOCRI, 1 female (MNRJ); INB0003713913 INBIOCRI, 1 macho (INBC); INB00034713907 INBIOCRI, 1 male (INBC); INB0003713915 INBIOCRI, 1 female dissected. Bratsi, Jardín (INBC), Valle Del Silencio. 2350. 10 oct 2000. M. Alfaro; INB0003462344 INBIOCRI, 1 male (INBC). P. Int. La Amistad, Send. Circular, 1400m, 23 mar 2003, R. Gonzáles; INB0003717287 INBIOCRI, 1 male (INBC); 2406m, 22 mar 2003, M. Alfaro; INB0003713133, INBIOI, 1 male (INBC); INB0003713000 INBIOCRI, 1 male (INBC); Est. Valle Del Silencio, 404 m, 26 mar 2003. R. González, D. Rubi, M. Alfaro, R. Delgado. Tp de Luz; INB0003717341 INBIOCRI, 1 male dissected (INBC). Prov. Punta, Est. La Casona, R. B. Monteverde, 1500 m. 10 feb 1994. M. Zumbado; INBIOCRI 001 678407, 1 male, without head (INBC). Prov. Cartago, P.N. Tapanté - Macizo de La Muerte, Camino a Rio Humo, 1200-1300, 23 ago 2002, M. Alfaro; INB0003542950 INBIOCRI, 1 male (INBC). Rio Macho, em el Alto el Rabble, 2200 m, 13 oct 1999. M. Alfaro; INB0003309472 INBIOCRI, 1 male (INBC). Prov. San José. San Gerardo de Dota, 2000-2500 m. 22-26 feb 1992; INBIO CRI 000407202, 1 male (INBC). Prov. Punta, Sam Luís, Monteverde, 1000-1350m. Feb 1994,2. Fuentes; INBIO CRI 001962231, 1 female (BMNH). Prov. S. José, F. Cementerio de la Máquina, 2100-2500, P. N. Chirripó, 2 mar 1993. M. A. Zumbado; INBIO CRI001 305775, 1 female (INBC).

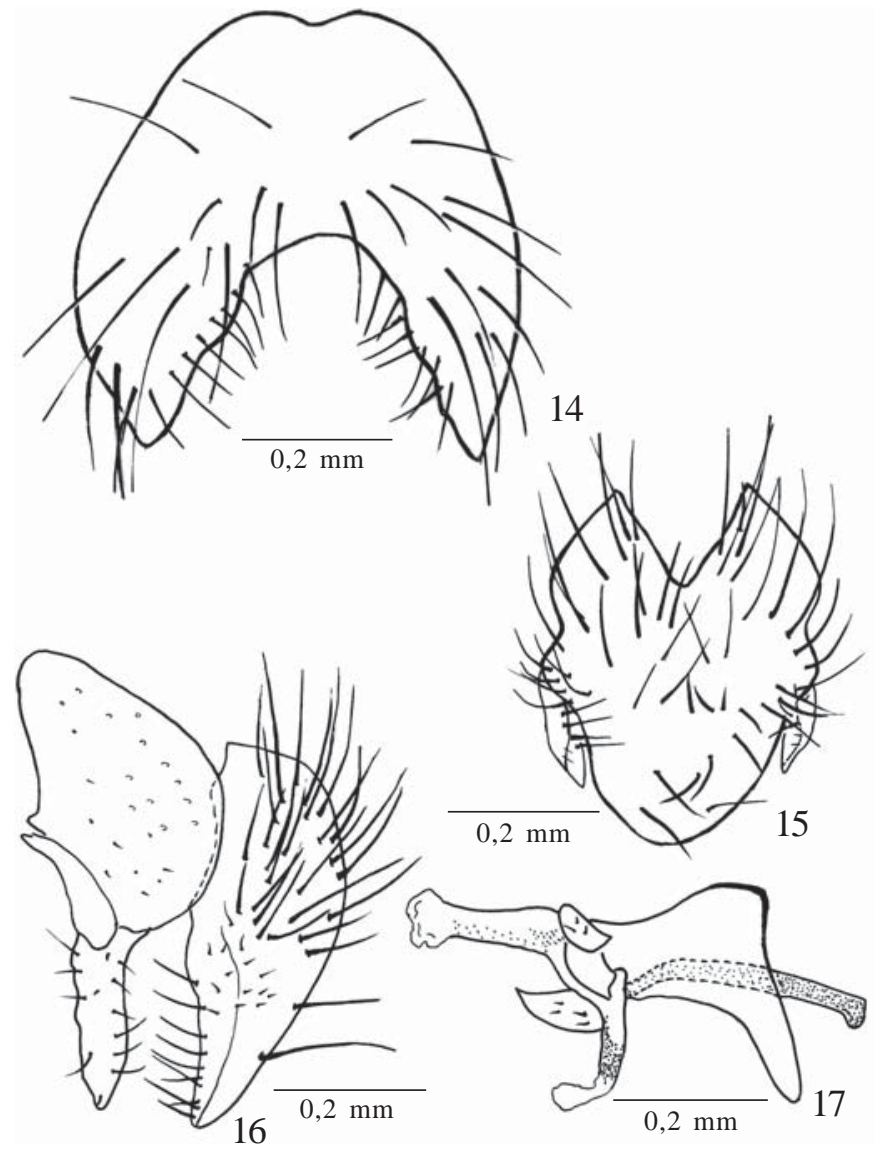

Figs. 14-17. Cordiluroides insularis (Williston). 14, Sternite 5, male, dorsal view; 15, Cercal plate and surstyli, dorsal view; 16, Epandrium, cercal plate and surstyli, lateral view; 17, Phallic complex, dorsal view.

\section{Cordiluroides insularis (Williston, 1896) (Figs. 4-5, 14-17)}

Coenosia insularis Williston, 1896: 371, pl. 12, figs 123 and 123a. Syntypes 3 males, BMNH. Type locality: St. Vincent Is. Distr. Mexico, St. Vincent Is., Colombia, Peru, Bolivia.

Cordiluroides insularis; Pont 1972: 44 (cat.; new combination).

Colour. Head with frons dark brown, face, fronto-orbital plate and gena grey pollinose; antenna and arista brown; palpus brown. Scutum bluish-brown with grey pollinosity, with 2 large lateral brown vittae. Pleura bluish-brown with grey pollinosity. Both calypters white; halter yellow. Wing of males faintly infuscated, darker on costal margin, and of females darker than in males along almost their entire length (Fig. 4). Legs brown with femoro-tibial joints paler, trochanters yellow. Pulvilli yellowish-white; claws black. Abdomen shining brownish-black (Fig. 5).

Length. Male: body: $9.5 \mathrm{~mm}$; wing: $9 \mathrm{~mm}$

Head. Interocular space about one-third of head-width at level of anterior ocellus. Three pairs of frontal setae, the lower two medium sized, the third long; one pair of medium-sized reclinate orbital setae. Ocellar setae long but shorter than the 
reclinate orbital. Antennae inserted a little above middle of eye; flagellomere about 3.6 times as long as pedicel. Arista short-pubescent. Vibrissa strong and long. Proboscis with developed teeth.

Thorax. Acrostichal setulae in 1-2 irregular rows, prescutellar pair not developed; dorsocentral setae $1+3$, all long and similar in length; 2 postpronotals, inner one short and delicate, outer one long; 1 presutural and 1 postsutural intra-alars; 1 presutural and 2 postsutural supra-alars. Scutellum with both basal and apical pair of setae long. Notopleuron with two setae, anterior one a little longer than posterior one. Anepisternum with a row of about 6 setae. Lower calypter about 1.6 as long as upper one. Fore femur with a row of sparse bristles on posterodorsal and posteroventral surfaces. Fore tibia with one long median posterior seta; one preapical dorsal, one posterior preapical and one posteroventral apical, these three short. Mid femur with 3-5 setae on basal two-thirds of anterior surface, posteroventral surface with a complete row of sparse setae; posterior surface with two preapical setae. Mid tibia with a sub-median anterior to anterodorsal seta, a long median posterior, one dorsal preapical seta, and apical setae on anterior and ventral surfaces, the latter strong. Hind femur with long, fine and sparse setae on anteroventral and posteroventral surfaces; two dorsal and one posterodorsal preapical setae. Hind tibia with a median anterodorsal and one short preapical, dorsal surface with one preapical seta, shifted well away from the tip of the tibia.

Abdomen. Tergites $1+2$ to 4 each with two pairs of lateral setae; tergite 5 with a row of marginal and discal setae. Sternite 5 quadrangular (Fig. 14).

Terminalia. Surstyli shorter than cercal plate (Figs 15 and 16). Phallic complex as in Fig. 17; hypandrium elongated.

Discussion. The colour of the abdomen and legs easily separate this species from the other two.

Material examined: COSTA RICA. Prov. Limón, P. Int. La Amistad, Send. Al Jardín. 2473 m, 20 mar 2003, D. Rubí, red de Golpe; NB0003714711 INBIO CRI, 1 male (INBC). Prov. Puntarenas, Coto Brus, Est. Biol. Las Altenas, Send Lecheria Abajo. 1340 m. 23 nov 2000. M. Alfaro. Manual; INB0003116056 INBIO CRI, 1 female (INBC).

Acknowledgements. MSC and CJBC are grateful to CNPq for their research grants (process numbers 300370/2004-0 and 304148/20024 , respectively) and for the financial support of their projects. CJBC is also grateful to Dr. Manuel Zumbado (Costa Rica) for study facilities during his visit to INBC. ACP thanks David Notton and Dr Joachim Ziegler, curators of the Diptera collections at The Natural History Museum, London, and the Museum für Naturkunde, Berlin, respectively, for access to the collections in their care.

\section{REFERENCES}

Albuquerque, D. de O. 1954. Fauna do Distrito Federal. XXI: Um gênero e três espécies novas de Coenosiinae (Diptera, Muscidae). Revista Brasileira de Biologia 14: 361-369.

Carvalho, C. J. B. de \& M. S. Couri. 2002. Part I. Basal groups. In: C. J. B. de Carvalho, (ed) Muscidae (Diptera) of the Neotropical Region: taxonomy. Curitiba. Editora Universidade Federal do Paraná, pp. 17-132.

Carvalho, C. J. B. de; M. S. Couri; A. C. Pont; D. Pamplona \& S. M. Lopes. 2005. A Catalogue of the Muscidae (Diptera) of the Neotropical Region. Zootaxa 860: 282 pp.

Couri, M. S. \& C. J. B. de Carvalho. 2002. Part II. Apical Groups. In: C. J. B. de Carvalho (ed) Muscidae (Diptera) of the Neotropical Region: taxonomy. Curitiba. Editora Universidade Federal do Paraná, pp. 133-262.

Couri, M. S. \& D. Gonçalves. 2002. Descrição de uma nova espécie de Cordiluroides Albuquerque (Diptera, Muscidae, Coenosiinae). Revista Brasileira de Entomologia 46: 77-79.

Couri, M. S. \& D. M. Pamplona. 1992. Cordiluroides Albuquerque, 1954 (Diptera, Muscidae, Coenosiinae): redescrições, notas, sinonímia e chave para as espécies. Revista Brasileira de Entomologia 36: 255-262.

Couri, M. S. \& A. C. Pont. 2000. Cladistic analysis of Coenosiini (Diptera, Muscidae, Coenosiinae). Systematic Entomology 25: 373-392, 74 figs.

Pont, A. C. 1972. Family Muscidae. In: A Catalogue of the Diptera of the Americas South of the United States. São Paulo. Museu de Zoologia, Universidade de São Paulo, 97: 111 pp.

Stein, P. 1918. Zur weitern Kenntnis aussereuropäischer Anthomyiden. Annales Historico-Naturales Musei Nationalis Hungarici, 16: $147-244$.

Stein, P. 1919. Die Anthomyidengattungen der Welt, analytisch bearbeitet, nebst einem kritisch systematischen Verzeichnis aller aussereuropäischen Arten. Archiv für Naturgeschichte, 83 A 1 [1917]: 85-178.

Williston, S. W. 1896. On the Diptera of St. Vincent (West Indies). Transactions of the Entomological Society of London, 1896: 253-446.

Wulp, F. M. van der (1896) Group Anthomyiinae. [Part.] In: F. D. Godman \& O. Salvin [eds.], Biologia Centrali Americana. Zoologia-Insecta-Diptera, London, 2 (part 132), pp. 321-344.

Wulp, F. M. van der (1897) Group Anthomyiinae. [Concl.] In: F. D. Godman \& O. Salvin [eds.] Biologia Centrali Americana. Zoologia-Insecta-Diptera, London, 2 (part 137), pp. 345-360.

Received 23/01/2006; accepted 04/09/2006 